\section{Open-label randomised pragmatic trial (CONTACT) comparing naproxen and low-dose colchicine for the treatment of gout flares in primary care}

We read with great interest the article by Roddy $e t a l^{1}$, published in the Annals of Rheumatic Disease, an open-label study that examined 399 patients presented at primary care centres with exacerbation of gout. The patients were allocated to two treatment arms, one group received naproxen and the second group treated with colchicine, and the primary outcome measured changes in the pain level from baseline over the first 7 days after presentation. Diarrhoea and headaches were more commonly reported in the colchicine group and given there was no difference between the two groups in the primary outcome, the authors recommended naproxen as the first line of treatment in acute gout arthritis, if no contraindication exists.

Although the authors pointed out that naproxen might be associated with decreased risk of cardiovascular events compared with the other non-steroidal anti-inflammatory drugs (NSAIDs) commonly used in gout, a recent metanalysis conducted by Bally et $a l^{2}$ demonstrated that all NSAIDs, including naproxen, have been linked to a higher risk of myocardial infarction. Therefore, given the evidence of serious adverse effects, we do not concur with the recommendation naproxen should be considered as the only first step treatment option. Furthermore, patients with a history of hypertension and/or diabetes mellitus were included in the study, and colchicine would be a reasonable first therapeutic option from a safety profile in this subgroup of patients.

Regarding the side effect profile, diarrhoea was evident in $45.9 \%$ of patients in the colchicine group versus $20 \%$ in the naproxen group, a significantly higher frequency compared with the $23 \%$ seen in the low-dose colchicine arm in the Acute Gout Flare Receiving Colchicine Evaluation (AGREE) trial. ${ }^{3}$ We wonder why the authors did not use a lower dose regimen from day 2 to 4 , for example, the prophylactic dose regime of $0.5-1 \mathrm{mg} / \mathrm{day}$, a widely use dose with an acceptable safety profile supported by the European League Against Rheumatism guidelines. ${ }^{4}$

Lastly, given the individual patient's characteristics, comorbidities, preferences and shared decision making, we believe that
NSAIDs and colchicine have an essential role in the management of gout flares, and both regimens can be used as first-line treatment.

\section{Konstantinos Parperis $\odot^{1,2}$}

${ }^{1}$ Internal Medicine, Division of Rheumatology, University of Cyprus Medical School, Nicosia, Cyprus

${ }^{2}$ Medicine, University of Arizona College of Medicine Phoenix, Phoenix, Arizona, USA

Correspondence to Dr Konstantinos Parperis, Internal Medicine, Division of Rheumatology, University of Cyprus Medical School, Nicosia 1678, Cyprus; kparpe02@ucy.ac.cy

Contributors KP is the only author of the correspondence letter. KP has contributed to the planning, conduct and reporting of the work described in the article.

Funding The authors have not declared a specific grant for this research from any funding agency in the public, commercial or not-for-profit sectors.

Competing interests None declared.

Patient consent for publication Not required.

Provenance and peer review Not commissioned; internally peer reviewed.

(c) Author(s) (or their employer(s)) 2019. No commercial re-use. See rights and permissions. Published by BMJ.

$$
\text { A) Check for updates }
$$

To cite Parperis K. Ann Rheum Dis Epub ahead of print: [please include Day Month Year]. doi:10.1136/annrheumdis-2019-216643

Received 13 November 2019

Accepted 17 November 2019

Ann Rheum Dis 2019;0:1. doi:10.1136/annrheumdis-2019-216643

ORCID ID

Konstantinos Parperis http://orcid.org/0000-0001-6009-0130

\section{REFERENCES}

1 Roddy E, Clarkson K, Blagojevic-Bucknall M, et al. Open-label randomised pragmatic trial (contact) comparing naproxen and low-dose colchicine for the treatment of gout flares in primary care. Ann Rheum Dis 2019:annrheumdis-2019-216154.

2 Bally M, Dendukuri N, Rich B, et al. Risk of acute myocardial infarction with NSAIDs in real world use: bayesian meta-analysis of individual patient data. BMJ 2017;357.

3 Terkeltaub RA, Furst DE, Bennett $\mathrm{K}$, et al. High versus low dosing of oral colchicine for early acute gout flare: twenty-four-hour outcome of the first multicenter, randomized, double-blind, placebo-controlled, parallel-group, dose-comparison colchicine study. Arthritis Rheum 2010;62:1060-8.

4 Richette P, Doherty M, Pascual E, et al. 2016 updated EULAR evidence-based recommendations for the management of gout. Ann Rheum Dis 2017;76:29-42. 